Article

\title{
Saudi Arabia's Solar and Wind Energy Penetration: Future Performance and Requirements
}

\author{
Fahad Alharbi *(D) and Denes Csala $\mathbb{D}$ \\ Engineering Department, Lancaster University, Lancaster LA1 4YR, UK; d.csala@lancaster.ac.uk \\ * Correspondence: f.alharbi@lancaster.ac.uk or fa7ad-1@hotmail.com
}

Received: 25 December 2019; Accepted: 23 January 2020; Published: 27 January 2020

check for updates

\begin{abstract}
Saudi Arabia fully depends on fossil fuels such as oil and natural gas to generate its electricity. Fossil fuels may have limited life and a history of fluctuating costs, which will lead to multiple issues that can affect the energy security of this country in the long-term. Critical Infrastructure Protection (CIP) is a concept different to "energy security", which must consider the solar and wind energy as basic sources of energy supplies in Saudi Arabia. Monte Carlo Simulation (MCS) and Brownian Motion (BM) approaches were employed to predict the future behaviour of solar and wind energy, along with long-term temperature performance, based on 69 years of historical daily data. MCS and BM were employed to provide a wide range of options for future prediction results. A validation exercise showed that the north-western region was the most highly recommended region for deployment of solar and wind energy applications due to an abundance of solar and wind energy resources with low temperature supported by a clearer sky during the year. This is followed by the southern region, which exhibited good solar and wind energy resources. This study can be considered as a roadmap to meet the climate and sustainability goals by providing a long-term overview of solar energy, wind energy, and temperature performance in some countries that have a lack of long-term future prediction analysis such as Saudi Arabia.
\end{abstract}

Keywords: prediction; Monte Carlo Simulation; Brownian Motion; solar and wind energy; Saudi Arabia; north-western region; southern region

\section{Introduction}

Technological advances in renewable energy, such as solar and wind energy, have made the generation of electricity through renewable energy resources a highly efficient and economically viable process, as well as the fastest-growing process in the power generation sectors globally. In the last two decades, Saudi Arabia has been optimising electricity generation from fossil fuels with renewable energy as a backup system [1]. Recently, Saudi Arabia's government has planned to shift towards renewable energy resources due to increases in power consumption and restrictive environmental regulations [1]. Carbon dioxide and greenhouse gas emissions can be reduced by applying renewable energy technologies. Since the late 19th century, the global average temperature of Earth's surface has increased by $0.6^{\circ} \mathrm{C}\left( \pm 0.2^{\circ} \mathrm{C}\right)$ due to climate change and global warming [2]. Regionally, during the dry seasons, the temperature has risen $0.72{ }^{\circ} \mathrm{C}$ per decade [2]. As the climate becomes warmer, evaporation increases, leading to an increase in average worldwide precipitation [1]. The combined impacts of fossil fuels on global warming have made implementing solar and wind energy in the 21st century a top priority [3]. The absence of harmful emissions, the rapid development in these technologies, and the decreasing cost of renewable energy have made solar and wind energy the most promising alternatives to fossil fuels in recent years [4,5]. However, the dependence on weather and nature fluctuations, which are difficult to predict, is a common drawback of solar and wind energy resources $[4,6]$. These issues could be partially confronted by applying the strengths of one source 
to overcome the weaknesses of the other source, but this integration makes hybrid solar and wind generation systems more difficult to analyse in some cases $[4,6]$. The variability and uncertainty of solar and wind energy resources create new challenges that can cause quick increases or decreases in power generation [7]. Solar and wind energy vary over time due to the influence of meteorological fluctuations. These normal variations occur across seconds, minutes, hours, days, weeks, months, seasons, and years. Solar and wind energy resources at prospective geographical locations must be investigated for economical utilisation [8]. The key for optimal utilisation and integration of solar and wind power is understanding these variations and their predictability. Forecasting modelling tools are widely used to assist utilities to manage grid operation by advising estimated renewable generation in advance [9]. Various numbers of research have been conducted throughout the world to discuss forecasting models to assess electricity generation from solar and wind sources in advance. A great prediction solution system was proposed by Shafiullah [9] as a hybrid integration system which can predict solar and wind generation in advance, supported by a model that can analyse the techno-economic and environmental prospects of renewable energy; as well as a load management system in order to manage customer load demand efficiently. The comprehensive proposed system was developed to be applied in a subtropical climate of Central Queensland. Moreover, these types of effective models can support the implementation of solar and wind energy in many locations due to the high quality of efficiency and cost reductions. In order to maximise the resultant benefits and maintain reliability at the required level, advanced tools for handling solar and wind energy, such as future-forecasting and management algorithms, can be employed. Solar and wind energy forecast tools that predict the next hours, days, and weeks can play a crucial role in the processes of management operator systems. Al-Alawi and Al-Hinai [10], Lopez et al. [11], and Mohandes et al. [12] conducted a search to develop predictive models to forecast solar irradiation based on an Artificial Neural Network by machine learning. The majority of these models achieved a high forecasting accuracy. The field of renewable energy forecasting has developed quickly due to increasing of total renewable energy share in many countries. Ji et al. [13] discussed a forecasting model used to predict mean hourly wind speed using a Support Vector Machine (SVM) technique. The proposed model is a novel algorithm for wind speed prediction, and forecasting error is improved by a support vector classifier, which is better than the transitional support vector regression algorithm. More and Deo [14] applied a technique to predict daily, weekly, and monthly wind speeds at two coastal sites in India using an Artificial Neural Network. Satisfactory prediction values with low deviations and high correlation observed. This type of forecasting technique was applied, trained with past data in auto-regressive manner by back propagation and cascade correlation algorithms. However, prediction accuracy reduced as the interval of prediction decreased, for example, from one month to one day. The majority of predictive models discussed in previous studies were built to cover the short or medium term, while there is a requirement to build a long-term predictive model due to cost-effective, energy saving, and climate requirements. The analyses of large historical solar and wind speed data from meteorological measurements and system operators at typical site locations allow determination of the future variations in net generated power, which can be expected for a long-term period. Furthermore, to assess the economic feasibility of solar and wind power generation projects, several optimisation approaches can be employed to analyse the performance of solar and wind resources for the long-term [4]. Optimisation modelling and statistical analyses can be employed to provide an effective solution to select the suitable sites to deploy solar plants and wind farms in order to generate large-scale power from renewable sources which significantly reduce the cost of power generation and eliminates $\mathrm{CO}_{2}$ emissions [15]. There is a need for developing predictive solutions due to sustainability requirements and climate change issues. Probabilistic forecasting is one of the flexible management tools that is enabling a movement from deterministic to stochastic methods to find robust solutions. The probabilistic approach can be implemented in this research to evaluate solar and wind resources behaviour based on Monte Carlo simulations (MCS) and Brownian Motion (BM), based on a large size of historical data in order to provide a wide range of options for future predicted values. Therefore, this paper aims to analyse 
the solar and wind resources in specific locations to support the integration of solar and wind energy generation projects. Furthermore, this paper synthesises the positive criteria of renewable energy's benefits and attempts to compensate for its deficiencies. This research simulates the future performance of solar and wind energy penetration scenarios in Saudi Arabia, and evaluates three selected cities: Riyadh in the central region, Tabuk in the north-western region, and Sharurah in the southern region, which represent different climate profiles. This study examines the distributions of changes in solar irradiance, wind speed, and temperature that may occur at different timescales during a long-term period. Although this research is employed to study the future performance of solar and wind resources in Saudi Arabia as a case study, it can be applied to other countries once a large amount of historical data is available, especially for the Gulf Cooperation Council (GCC) countries, which have the same geographical locations and climatological conditions.

The structure of this paper is organised as follows: Section 2 discusses the solar and wind energy resources in Saudi Arabia. The methods of this research, including the main approach and framework, are presented in Section 3. Section 4 contains the results and discussion. Finally, conclusions are provided in Section 5.

\section{Solar and Wind Energy Resources in Saudi Arabia}

Solar and wind energy are presented as a key source for the future of energy in Saudi Arabia, and the world. The worldwide developments of solar and wind energy have encouraged the research and scientific communities to conduct a series of investigations to analyse potential solar and wind energy resources in Saudi Arabia [8]. Saudi Arabia has contributed major international renewable energy research, such as the SOLERAS program that was established 31 years ago [16]. Additionally, King Abdulaziz City for Science and Technology (KACST) focuses on solar and wind energy studies and conducting appropriate applied research to develop technical feasibility for its localisation in Saudi Arabia. KACST helped to develop a wind energy atlas for research projects in Saudi Arabia, in cooperation with the United States Joint Program [17]. The atlas platform resources provide profiles of wind speed data, such as the frequency distribution of wind directions and the diurnal variations of mean wind speeds from several airport meteorological stations. Furthermore, King Abdullah City for Atomic and Renewable Energy (KACARE) has launched a more comprehensive Renewable Resource Atlas in order to provide a solar and wind energy resource-monitoring system for live data recorded from 41 stations across the country for the use of researchers, developers, policy-makers, government institutions, and those working in risk-reduction [18]. KACARE has developed a Renewable Resource Monitoring and Mapping (RRMM) program, which is in cooperation with the Battelle Memorial Institute and the United States-Based National Renewable Energy Laboratory to assist and evaluate the potential of solar and wind energy [19]. The KACST and KACARE platforms monitor network resources aimed to measure and record solar and wind energy data at different locations in Saudi Arabia to improve renewable energy technologies $[19,20]$.

\subsection{Historical Solar and Wind Energy Performance}

Saudi Arabia represents a variety of geographical locations and climatological conditions. In order to select the most suitable locations for wind farms and solar power plants, especially for the early deployments of these technologies, the historical performance of solar and wind energy will be investigated in the following sections.

\subsubsection{Solar Energy}

Alharthi et al. [21] analysed the performance of solar energy in four selected cities in Saudi Arabia: Riyadh (central region), Sharurah (south region), Hafar Albatin (north-eastern region), and Yanbu (western coast). According to Alharthi et al. [21], the monthly total global horizontal irradiance (GHI) and the direct normal irradiance (DNI) levels were high at all of the selected sites and supported by relatively low variability. Alharthi et al. [21] summarised the solar irradiance behaviours of the 
four sites. Furthermore, Sharurah site recorded the highest annual average daily total of GHI and DNI values, while the lowest values were observed at the Hafar Albatin site. Yanbu site reached the second highest values of GHI and DNI [21]. The diffuse horizontal irradiance (DHI) values were close across the four sites. The highest value of DHI was observed at Riyadh site, and the lowest value was observed at Yanbu site. Zell et al. [19] conducted a study to investigate the performance of solar energy and temperature at 30 sites, including Riyadh, Sharurah, and Tabuk (north-western region). Zell et al. [19] agreed with Alharthi et al. [21] that all the sites recorded high values of GHI with low variability. These GHI values are well-suited for strong photovoltaic (PV) technology and solar power plants across Saudi Arabia [19]. Nevertheless, the temperatures in some sites were extremely high (over $30^{\circ} \mathrm{C}$ ), which can relatively impact the behaviour of solar power plants [19]. The north-western region of the country showed higher DNI levels, supported by a clearer sky during the year. These results can have a strong influence on decisions such as location selection for solar power plants, technology selection, the creation and validation of solar resource forecasts, and support for utility scale plant operation. Almarshoud [22] conducted a study to explore the relative properties of solar energy performance in 32 sites around Saudi Arabia by applying three types of sun-tracking modes, such as fixed tilt angle, 1-axis tracking, and 2-axis tracking. Based on Almarshoud [22], the northern region of Saudi Arabia, such as Timma and Tabuk sites, produced high solar energy productivity due to high average solar irradiance and low average temperatures. Similarly, the two sites of Sharurah and Najran in the southern region of Saudi Arabia reached high average values of solar irradiance. Meanwhile, the Qunfudhah site on the Red Sea coast recorded the lowest values of average solar irradiance [22]. Ramli et al. [23] debated a technical and economic analysis that showed that the west coast region has sufficient potential energy from solar power to generate electricity. Another study was conducted by Abu-Hamdeh and Alnefaie [24] to evaluate solar energy and to investigate the appropriateness of a concentrated solar power (CSP) system in Jeddah. The results showed that the solar intensity is higher than the required critical values. Extended research was conducted by Dasari et al. [25] to evaluate the solar energy resources over the Arabian Peninsula, including Saudi Arabia, across 38 years (1980-2017). The data were collected from 46 in-situ radiometer stations to analyse the GHI, DNI, and DHI. In particular, the main observations were that the south-eastern to north-western regions of Saudi Arabia are the most suitable regions to exploit solar energy with minimal cloud coverage [25]. Moreover, the GHI and DNI values are high over the western and south-western regions of the Red Sea. The reanalysis and review of solar energy resources over Saudi Arabia as initial and boundary conditions assimilated the most available observations in the country. Overall, the investigation of previous studies and the historical solar energy data showed that the south-eastern and north-western regions of Saudi Arabia can be subjects of study to implement solar energy technologies, as these regions are supported by a minimum of cloud coverage and low temperatures. Due to its widespread, unused desert land and the abundance of solar energy resources (presented in Figures 1-3), Saudi Arabia has great potential opportunities to harness solar sources for solar energy applications. If a breakthrough is achieved in the solar energy fields, Saudi Arabia can be a leading producer and exporter of solar energy generation. However, solar energy technologies' performance in Saudi Arabia requires a long-term future forecasting analysis. Forecasts need to be updated continuously for more evaluations of solar energy resources in Saudi Arabia, which will have different economic and system reliability benefits during different periods. 


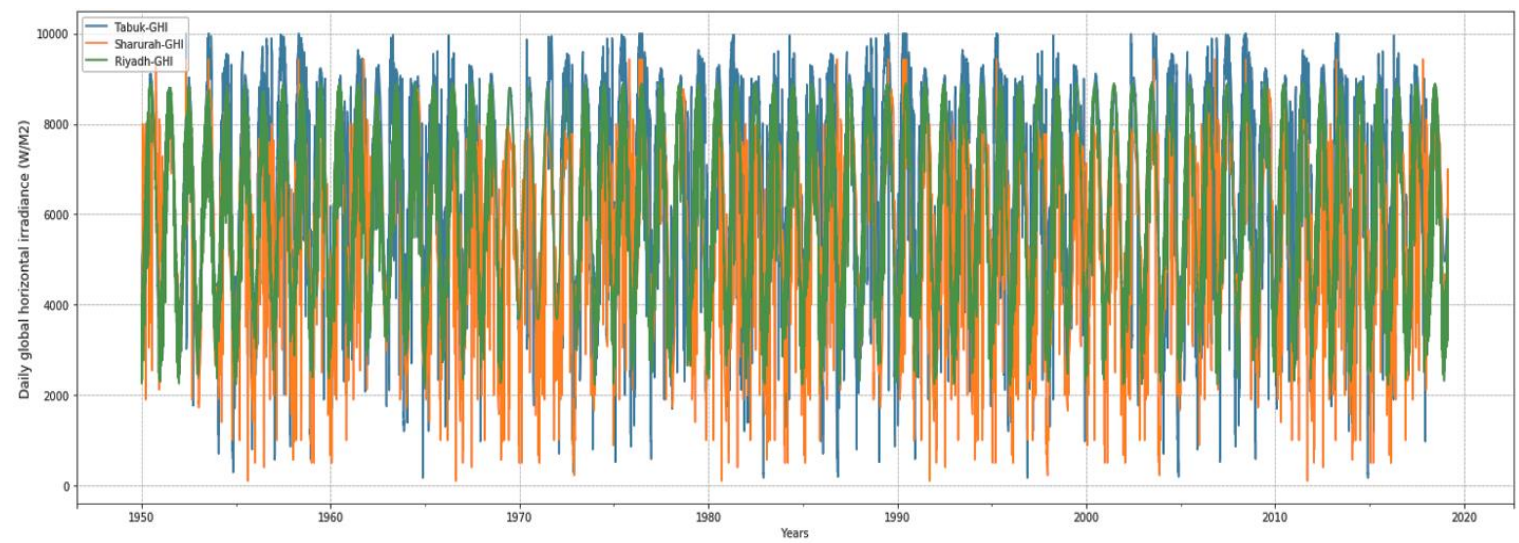

Figure 1. The global horizontal irradiance performance of the three regions.

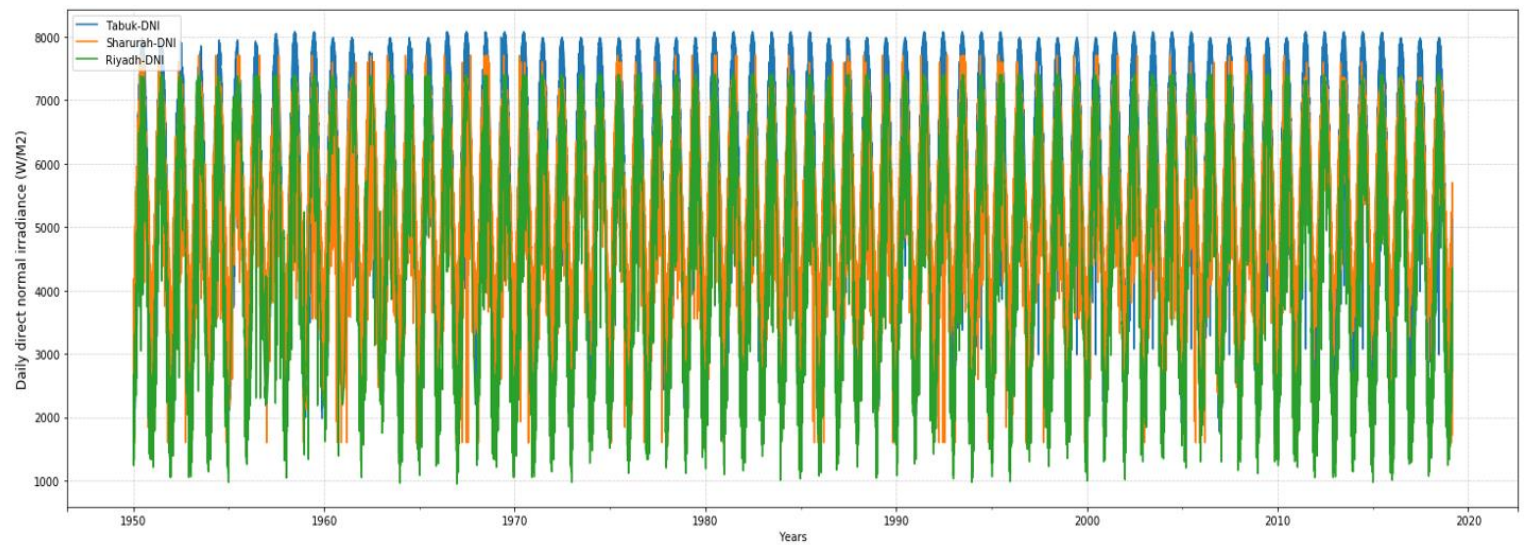

Figure 2. The direct normal irradiance performance of the three regions.

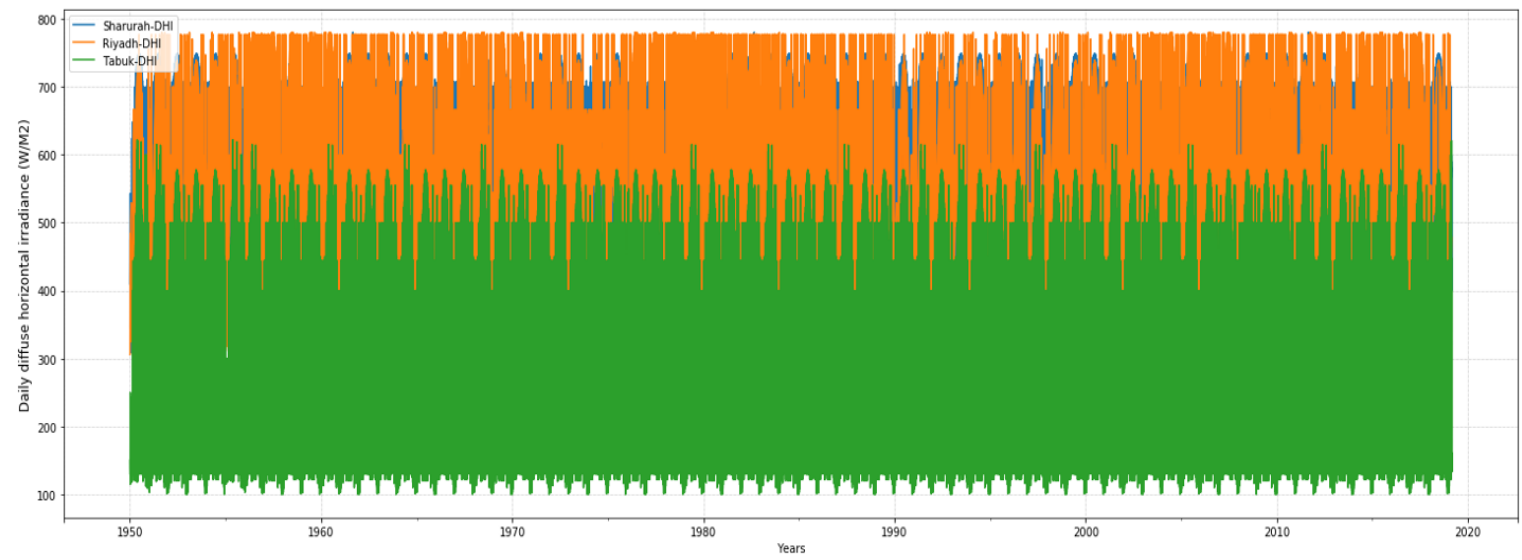

Figure 3. The diffuse horizontal irradiance performance of the three regions.

\subsubsection{Wind Energy}

Alharthi et al. [21] analysed wind speed distribution frequency in Riyadh (central region), Sharurah (south region), Hafar Albatin (north-east region), and Yanbu (west coast), and found that the probabilities of wind speed reaching $10 \mathrm{~m}$ per second $(\mathrm{m} / \mathrm{s})$ or higher at an $80-\mathrm{m}$ maximum height were $41 \%$ at Yanbu site, with 27\% at Hafar Albatin site, 22\% at Sharurah site, and 14\% at Riyadh site. Rehman and Ahmad [26] performed an analysis of wind speed distribution at different heights (10, 40, 50, and 60 m) for five coastal locations in Saudi Arabia: Yanbu, Dhahran, Al-Wajh, Jeddah, and Gizan. According to Rehman and Ahmad [26], for harnessing wind power, Yanbu is the best coastal location, and Dhahran 
is the next best location for wind power generation. The analysis of monthly average wind speed showed higher wind speeds available in the summer season at Dhahran, Yanbu, and Gizan, while the impact of season was insignificant at Al-Wajh and Jeddah sites [26]. Al-Abbadi [8] conducted a study to analyse the wind energy potential at five sites in Saudi Arabia: Dhahran, Yanbu, Arar, Gassim, and Dhulum. According to Al-Abbadi [8], Dhulum and Arar sites have higher wind energy potential, with 5.7 and $5.4 \mathrm{~m} / \mathrm{s}$ annual average wind speeds, respectively. Dhulum and Arar have isolated, scattered, and low population areas that support the economic feasibility of wind power being used at these locations, as it is recommended to use remote areas for wind farm projects. Baseer et al. [27] performed an assessment to evaluate the wind speeds at different heights above ground level (10, 50, and $90 \mathrm{~m})$ for five sites at Jubail industrial city in the eastern province in Saudi Arabia. Based on Baseer et al. [27], the highest mean wind speeds at the Jubail industrial site of $5.35 \mathrm{~m} / \mathrm{s}$, and the possibility of wind speeds reaching above $3.5 \mathrm{~m} / \mathrm{s}$, was $75 \%$. Another study was conducted by the same team [28] to analyse seven sites at Jubail using different tools. The results showed that the highest annual mean wind speed of $4.52 \mathrm{~m} / \mathrm{s}$ was observed at Jubail [28]. Shaahid et al. [29] studied the economic feasibility of wind energy potential for four coastal sites in the western region at a height of $10 \mathrm{~m}$ : Al-Wajh, Jeddah, Yanbu, and Jizan. The study indicated that the maximum yearly wind speed average was $5 \mathrm{~m} / \mathrm{s}$ [29]. Research performed by Rehman et al. [30] to explore the possibility of establishing a wind farm in the eastern region in Saudi Arabia recorded $5.74 \mathrm{~m} / \mathrm{s}$ as the highest mean wind speed in the region at a height of $40 \mathrm{~m}$. Furthermore, it was observed that higher wind speed values were recorded during the day and during the summer season, while lower wind speed values were recorded during the night and during the winter season [30]. Elhadidy and Shaahid [31] conducted research to exploit renewable energy resources and focus on wind energy performance in the eastern coastal region. The analysis indicated that the monthly average wind speed was $5.8 \mathrm{~m} / \mathrm{s}$, which is relatively close to the findings of Rehman et al. [29]. Another study was conducted by Rehman et al. [32] to investigate the wind energy characteristics in the city of Rafha in the northern region of Saudi Arabia. The results showed that the maximum annual mean wind speed value was $4.9 \mathrm{~m} / \mathrm{s}$ at Rafha site, and the possibility of reaching higher than $6.5 \mathrm{~m} / \mathrm{s}$ was 20\% [32]. In addition, Yip et al. [33] evaluated the wind energy in the Arabian Peninsula, including Saudi Arabia. According to Yip et al. [33], the coastal regions along the Arabian Gulf have more variable wind resources compared to their Red Sea counterparts at similar latitudes. Along the coast of the Arabian Gulf, persistent wind speed was observed, and more abundant wind resources were found in the western mountains of Saudi Arabia compared to most Red Sea coastal areas [33]. Based on the historical wind speed measurements (shown in Figure 4) and the evaluation of wind speed frequency distributions for different sites in Saudi Arabia, the wind resources reached relatively high levels along the coastlines. The wind speed was observed to be greater in the western mountains and the northern region, with good opportunity performance in the southern region of Saudi Arabia. In view of this, an appreciable fraction of these regions' energy requirements can be harnessed from wind energy resources. To facilitate large-scale exploitation of wind energy for a sustainable future, wind resource assessments for different regions of Saudi Arabia need to be carried out to meet an appreciable portion of the energy requirements. In order to promote wind energy utilisation as a form of clean energy and to mitigate a possible future energy crisis, investment in wind energy is imperative. 


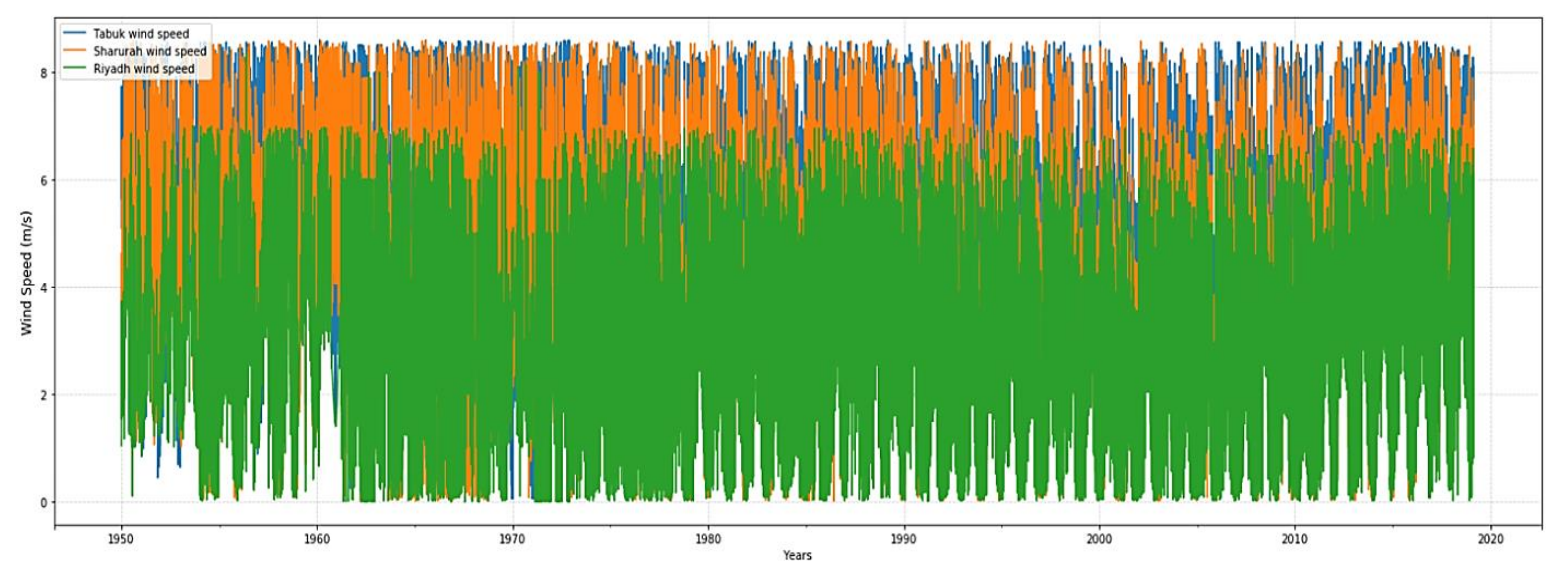

Figure 4. The wind speed performance of the three regions.

Saudi Arabia fully depends on fossil fuels such as oil and natural gas to generate its electricity. The fossil fuels may have limited life and a history of fluctuating costs, which will lead to multiple issues that can affect the energy security of this country during the long-term. Critical Infrastructure Protection (CIP) is a concept that is different from "energy security" which must consider renewable energy (solar and wind energy) as a basic source of energy supplies in Saudi Arabia. Furthermore, increasing fossil fuel energy consumption impacts Saudi Arabia's economy growth and leads to a rise in environmental issues, such as increasing the $\mathrm{CO}_{2}$ rate in the region, as well as Global Warming. Implementation of renewable energy technology shares in Saudi Arabia's total energy generation can be the suitable solution for all fossil fuel issues. In addition, there is a lack of renewable energy (solar and wind) research and studies of these technologies in Saudi Arabia, which are required to support renewable energy implementation and to diversify the energy mix. This research aims to assess a long-term contribution in sustainable energy strategy using smart tools that protect the power supply from fluctuations and volatility, and to reduce $\mathrm{CO}_{2}$ issues in Saudi Arabia. The research aims to spearhead the renewable energy transition towards with a more sustainable and equitable future.

\section{Methods}

Historical daily weather data were collected for the period 1950-2019 from eight weather in-situ radiometer stations around Saudi Arabia for the three selected cities: Riyadh in the central region, Tabuk in the north-western region, and Sharurah in the southern region. Historical weather data included temperatures, solar irradiances, and wind speeds at a height of $10 \mathrm{~m}$ as $\mathrm{km} / \mathrm{h}$. Wind speeds were measured at 150-m heights for all regions using Equation (1). The historical data are presented in Figures 1-5. Equations (1) and (2) represent the velocity profile by a power function and logarithmic function, respectively [34]. $U$ is the wind speed at a required height, Uref is the reference wind speed, $z$ ref is the anemometer height, $z$ is the required height, $s$ is the shape of the power-law profile, and $z o$ is the surface roughness length.

$$
\begin{gathered}
\frac{U}{\text { Uref }}=\left(\frac{z}{z r e f}\right)^{s} \\
\frac{U}{\text { Uref }}=\left(\frac{\operatorname{Ln}(z / z o)}{\operatorname{Ln}(z r e f / z o)}\right)
\end{gathered}
$$




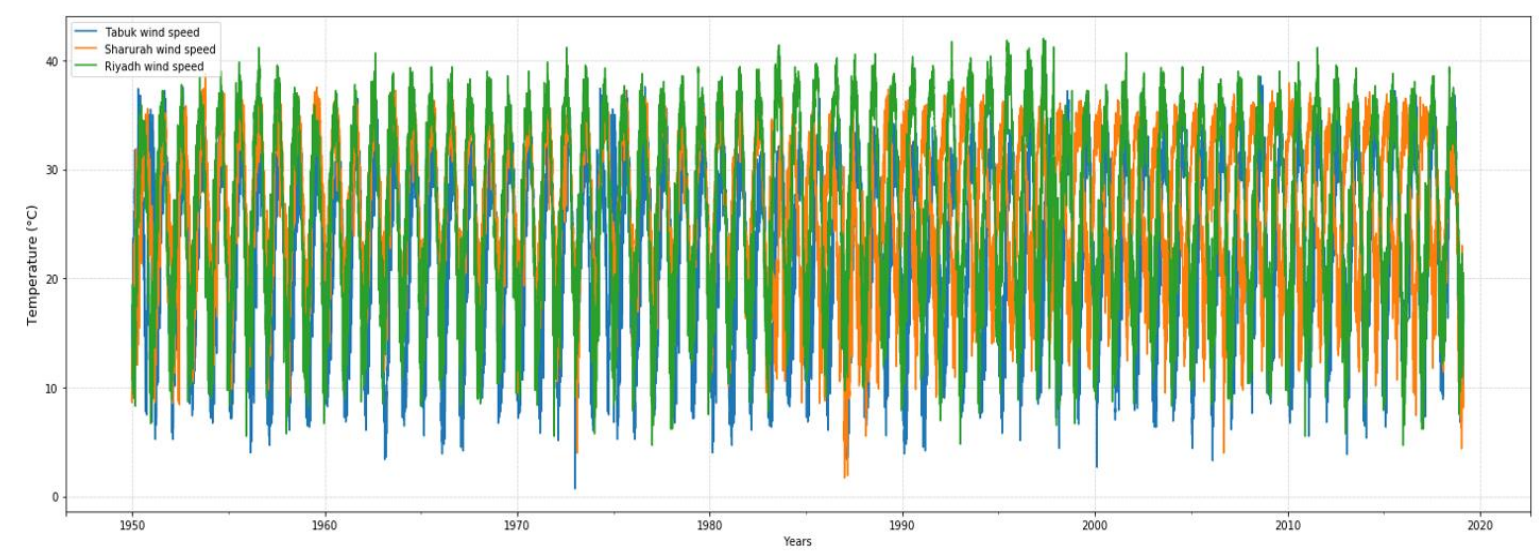

Figure 5. The average temperature performance of the three regions.

Monte Carlo Simulation (MCS) and Brownian Motion (BM)

MCS and BM were employed herein to estimate the future performance of solar and wind energy with the behaviour of temperature for the three selected sites in Saudi Arabia [35]. MCS is a computerised mathematical technique employed to produce random values based on a known distribution of the historical data. MCS was applied to model the probabilities of several outcomes, which cannot be easily predicted due to the intervention of random variables to understand the distribution and uncertainty in a prediction model. This approach is a form of quantitative analysis that is employed to randomly calculate the Sharpe ratio for thousands of selected allocations. MCS and BM were employed to refer to a universe of different simulation approaches, such as future energy prediction scenarios, which help researchers make informed decisions. BM is technically a Markov process, which means the values follow a random walk, and is consistent with the weak form, and past value information is already incorporated, and the next estimated value's movement is "conditionally independent" of past values movements. Standard Brownian motion (BM) is a stochastic process when $B=\{B(t): t \geq 0\}$ as continuous sample paths. The ultimate aim of describing the details of $B M$ and MCS processes are to use these concepts for real option theory application. The new generated dataset is larger than the historical initial dataset, which would provide immense opportunities to understand and analyse the produced scenarios. It would be a big challenge to generate accurate long-term prediction, which depends on the size of the historical data and suitable selected approaches. These are common issues with all approaches that are used to build future scenarios, but BM and MCS approaches have the great advantage of using a small amount of historical data, including generating unlimited future values, which can avoid this issue to generate long-term scenarios. Python software simulates and predicts the development of the values from 1000 to 10,000 times, which would generate the maximum and minimum expected average values. Python's package library is very extensive, offering a wide range of facilities and providing access to system functionality with large memory. The large memory is highly required in statistical processes, such as for huge historical data and large future predicated data. The holistic method process of historical data collection, including preparing the historical data and building the predictive model, is shown in Figure 6. In addition, Equations (3)-(5) were employed to produce the future values of wind speed, solar irradiance, and temperature [35]. D is the drift, $\mathrm{V}$ is the variance, $\mathrm{S}$ is the standard deviation, $\mathrm{u}$ is the average log value or the percentage drift, and $r$ is the long-share value and the natural logarithm of Brownian Motion. $S_{t}$ is the value for day $(t)$, while $S_{t-1}$ is the value observed on the previous day $(t-1)$ when standard deviation $=1$, mean $=0$, $\mathrm{Z}$ is the number of standard deviations, and $\delta$ is the step size of the latent variables. Furthermore, Equations (3)-(5) were implemented, and integrated in the codes in order to build a sufficient long-term predictive model. All the algorithms and variables of the BM and MCS approaches were defined based on Python's libraries, including Numpy, Pandas, and Scipy functions. The codes and predictive model were evaluated at multiple stages based on comparing different algorithms to each other, oftentimes in 
terms of computational and predictive performance, and selecting the best model efficiency from a specific hypothesis space, as shown in Figure 6.

$$
\begin{gathered}
\mathrm{D}=\mathrm{u}-\frac{1}{2} * \mathrm{~V} \\
\mathrm{r}=\mathrm{D}+\mathrm{S} * \mathrm{e}^{\mathrm{r}} \\
\mathrm{S}_{\mathrm{t}}=\mathrm{S}_{\mathrm{t}-1} * e^{\left(r-\frac{1}{2} * \mathrm{~S}^{2}\right) \delta_{\mathrm{t}}+\mathrm{S}\left[\sqrt{\delta_{\mathrm{t}}} \cdot \mathrm{Z}_{\mathrm{t}}\right]}
\end{gathered}
$$

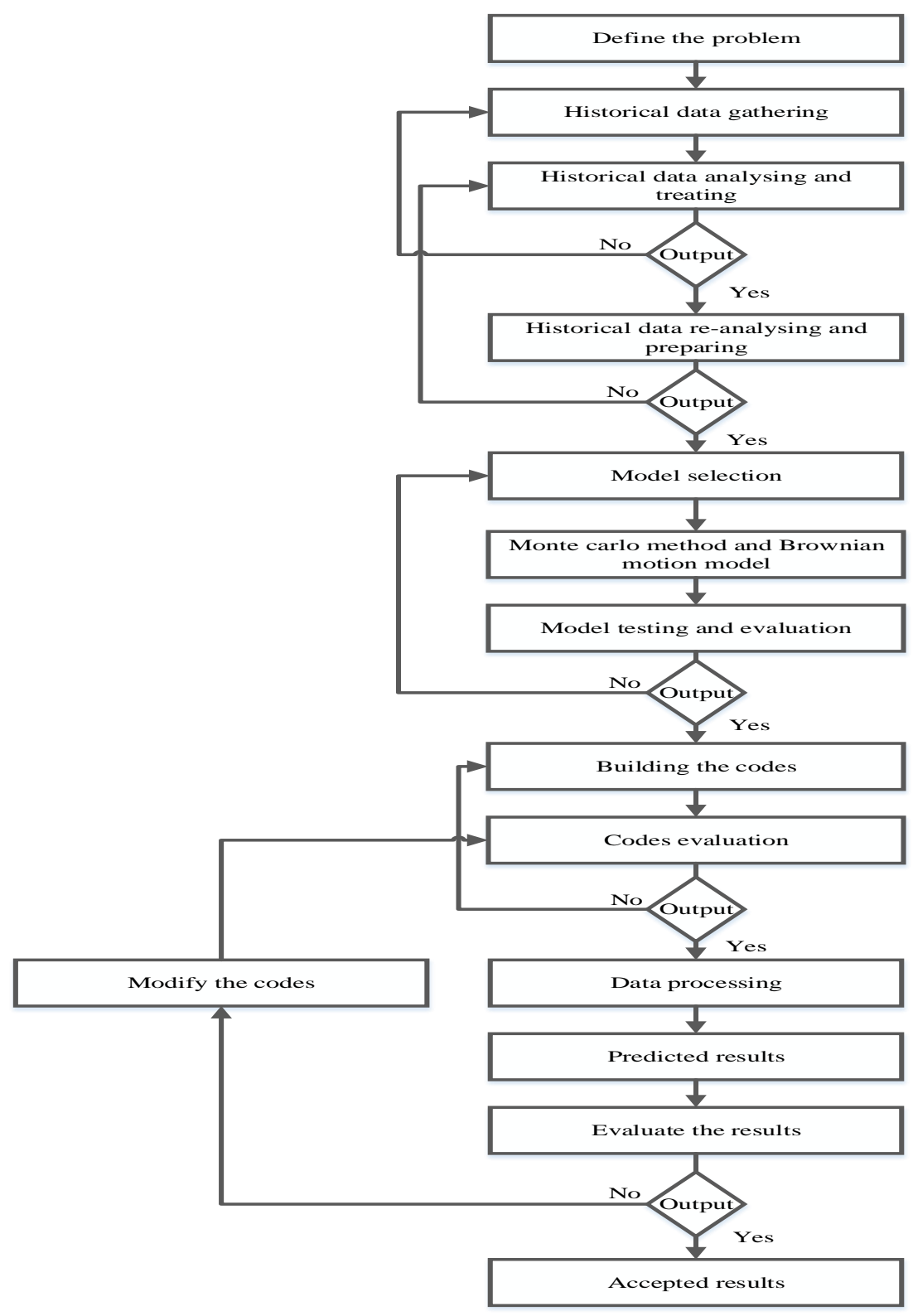

Figure 6. Method processes of historical data gathering, preparing, and building the predictive model.

\section{Results and Discussion}

In order to encourage the implementation of solar and wind energy in Saudi Arabia, the future performance of weather resources, such as solar irradiances, wind speeds, and temperatures, must be investigated and analysed for the long-term. Three regions in Saudi Arabia were selected to be the subjects for weather analysis and evaluation: the central region, the north-western region, and 
the southern region, to cover different climatological conditions. The daily total values of the GHI, DNI, and DHI were estimated to analyse their future behaviours. The weather patterns are somewhat random in different times and locations, and extremely difficult to predict without depending on historical data performance, while the historical data have a major impact on overall results due to the strong relationship of time series between the performance of historical data and future predicted values. The inherent variability of future values of solar irradiance, wind speed, and temperature of historical records are extremely useful for analytical and predictive tools, which are appropriate for a wide range of applications. According to the MCS and BM future analyses, the daily total values of $\mathrm{GHI}$ in the central region were predicted to reach $6089 \mathrm{Watts} /$ meter square $\left(\mathrm{W} / \mathrm{M}^{2}\right)$ as the highest value and $3240 \mathrm{~W} / \mathrm{M}^{2}$ as the lowest value, as shown in Figure $7 \mathrm{~b}$. In addition, the distribution performance describes the future daily behaviours of GHI at the central region, as illustrated in Figure 7a. On the other hand, the north-western region exhibited higher daily total solar GHI, which was estimated to reach the maximum and minimum values of $9050 \mathrm{~W} / \mathrm{M}^{2}$ and $5110 \mathrm{~W} / \mathrm{M}^{2}$, respectively, as indicated in Figure $8 \mathrm{~b}$, with an extremely highlighted distribution performance, as presented in Figure 8a. The southern region exposed a good daily total solar GHI distribution (Figure 9a), with the highest and lowest solar GHI values of 7600 and $5150 \mathrm{~W} / \mathrm{M}^{2}$, respectively. Furthermore, the maximum daily total value of DNI was $6490 \mathrm{~W} / \mathrm{M} 2$ with a minimum value of $2700 \mathrm{~W} / \mathrm{M}^{2}$ in the central region, as shown in Figure 10b. The north-western region was predicted to continue reaching high future DNI values, with 7449 and $3710 \mathrm{~W} / \mathrm{M}^{2}$ as the highest and lowest values, respectively, as presented in Figure $11 \mathrm{~b}$. The maximum daily total value of DNI in the southern region was estimated as $7203 \mathrm{~W} / \mathrm{M}^{2}$, with $3100 \mathrm{~W} / \mathrm{M}^{2}$ as the minimum value, as indicated in Figure $12 \mathrm{~b}$. Moreover, the daily total of DHI in the central region was expected to be $777 \mathrm{~W} / \mathrm{M}^{2}$ as the highest value and $425 \mathrm{~W} / \mathrm{M}^{2}$ as the lowest value, as shown in Figure 13b. The maximum and minimum daily total values of DHI in the north-western region were predicted to reach 531 and $220 \mathrm{~W} / \mathrm{M}^{2}$, respectively, as presented in Figure 14b. The highest and lowest daily total values of DHI in the southern region were estimated at 689 and $470 \mathrm{~W} / \mathrm{M}^{2}$, respectively, as indicated in Figure 15b. Based on the results of this study, the north-western region exhibited extremely promising daily solar irradiance resources, followed by good daily solar irradiances in the southern region. This makes these regions suitable for solar power plant projects, in addition to the fact that they are supported by vast open land with relatively low temperature values. These results can be ascribed to the central region generally, which has a history of long dust storms spells with typhoons, terrain and a significant lack of rain during the year, especially in the summer. Meanwhile, the north-western region is characterised by a distinguished location with a clear sky, free from dust, relatively low temperature, and a moderate climate throughout the year, which explains these very distinct results. The southern region is characterised by a history of lower temperature, dusty and cloudy weather during the year, with foggy days in some cases. The fact is that, on a clear day, the received direct solar irradiance represents between $85 \%$ and $90 \%$ of the total amount of solar irradiance reaching the surface of the earth. On a foggy or cloudy day, when we "cannot see the sun", the direct component of solar irradiance is essentially very low. The variation of all of these factors, including geographical locations and climate change issues, attenuate the direct component and change the solar irradiances. In general, a considerable amount of effort has been spent in cataloguing, measuring, and developing analytical predictive models to forecast these effects. However, the future evaluation of solar energy resources showed that Saudi Arabia has abundant potential solar energy resources available in the north-western and southern regions, which presents great opportunities to diversify Saudi Arabia's power system. Theoretically, the findings of this research show great incentives to push ahead with investments in solar energy.

The wind speed distributions levels were plotted in order to gain insight into the locations to permit extrapolation between the sites and the predicted results. The daily average wind speed measured in the three regions was predicted, and it was expected that 6.7 and $3.3 \mathrm{~m} / \mathrm{s}$ would be the maximum and minimum values in the central region, respectively, as shown in Figure 16b. In addition, the estimated highest and lowest daily average wind speeds in the north-western region were 8.5 and 
$5.8 \mathrm{~m} / \mathrm{s}$, respectively, with good wind speed distributions (Figure 17a). The southern region exhibited predictable maximum and minimum daily average wind speeds of 8.57 and $4.8 \mathrm{~m} / \mathrm{s}$, respectively, as illustrated in Figure 18b. The wind speed changes from one site to another due to various factors, such as different geographical locations and meteorological (differences in the atmospheric pressure) conditions. In general, Saudi Arabia is characterised by a wide desert area, with a very dry climate, and some mountainous areas in the southern region, valleys in the central region, some small hills in the north-western region, and agricultural areas in the north-western and southern regions. The effect of terrain features that may cause local variations in wind speed was reflected in the predicted values wind speeds. Based on the MCS and BM future analyses, the north-western and southern regions have acceptable wind energy resources for the long-term, and the two regions are suitable for wind farm projects in Saudi Arabia. Hence, modern wind turbines are variable-speed machines and have different wind speeds that depend on the characteristics of the selected and installed wind turbines, such as the size. In this regard, the cut-in and cut-out wind speeds of the wind turbines are 3.5 and $25 \mathrm{~m} / \mathrm{s}$, respectively. Furthermore, the average wind speeds in a particular region are required to achieve at least $6-8 \mathrm{~m} / \mathrm{s}$ to be economically viable.

According to the MCS and BM future predictions, the minimum and maximum daily average temperatures of the central region were 16.3 and $46.4^{\circ} \mathrm{C}$, respectively. Figure $19 \mathrm{~b}$ shows the performance of the daily average temperature of the next 10,000 days of the future, starting from 20 February 2019. Figure 19a presents a high concentration of average temperature intensity in the central region, between $10{ }^{\circ} \mathrm{C}$ in the winter and $45^{\circ} \mathrm{C}$ in the summer during the next 27 years. The north-western region exhibited lower daily average temperature values for the future, which were expected to be 33.3 and $13^{\circ} \mathrm{C}$ as the highest and lowest values, respectively. Figure 20a shows the concentration of average temperature distribution in the region. Furthermore, the southern region exhibited the maximum and minimum daily average temperatures of 30.4 and $13{ }^{\circ} \mathrm{C}$, respectively, as shown in Figure 21. Compared to the other two regions, the southern region recorded lower daily average temperature values due to dusty weather during the summer, in some cases, on the whole, and cloudy weather during the winter; however, relatively, it can support the implementation of solar power plants. Meanwhile, the southern region is characterised by a clear sky throughout the year and a lesser dust rate, which makes it more suitable for solar system power plants due to low cost of cleaning the solar panels. The temperature values play an important role in solar power generation: as the temperature values increase, the current values rise very slightly, and the voltage values decrease more rapidly. Higher temperatures generally eliminate the power outputs of solar plants and increase power losses.

A validation exercise showed that the north-western region is the most highly recommended region for deployment of solar and wind energy applications due to abundance of solar and wind energy resources supported by low temperature. This is followed by the southern region, which exhibited good solar and wind energy resources. The two regions were classified based on their overall of 69 years of historical data for daily solar irradiances, wind speed, and daily average temperature behaviour, with 27 years of future predicted value performance. Furthermore, an interesting aspect from this paper is that this study can be considered as a roadmap to meet the climate and sustainability goals by providing a long-term overview of solar, wind energy, and average temperature performance in some countries that have a lack of long-term future prediction analysis, such as Saudi Arabia. The findings of this research can be used by a decision-maker for renewable energy development in Saudi Arabia. 


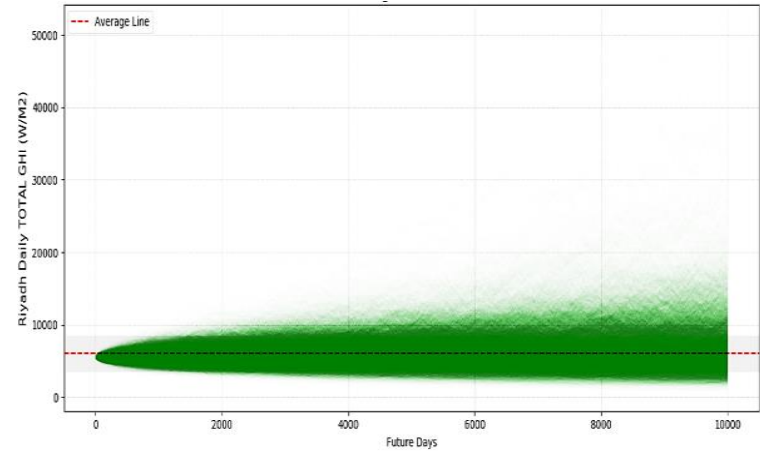

(a)

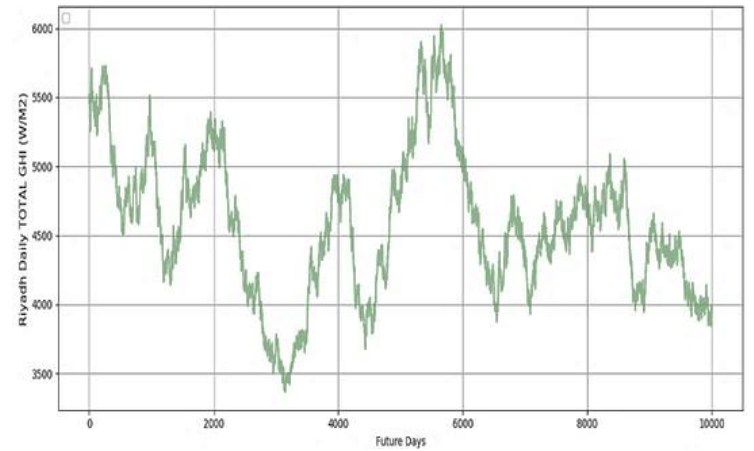

(b)

Figure 7. (a) Daily total solar global horizontal irradiance (GHI) distributions for the central region, as predicted by Monte Carlo Simulation (MCS) and Brownian Motion (BM), and (b) a one-day scenario for the solar GHI distribution prediction performance.

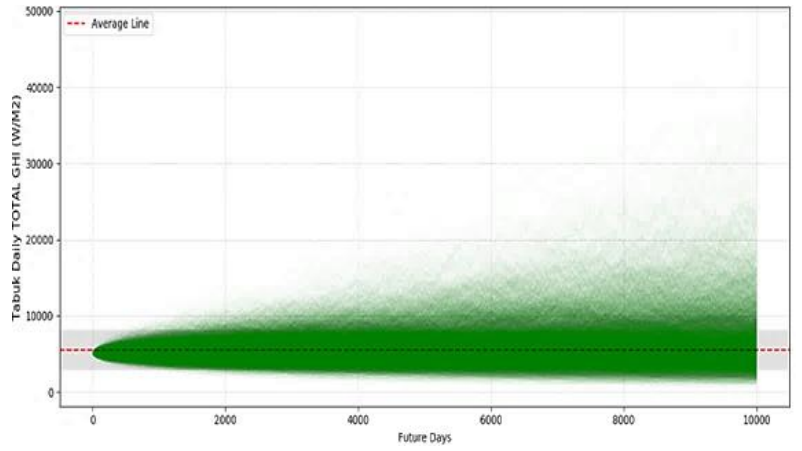

(a)

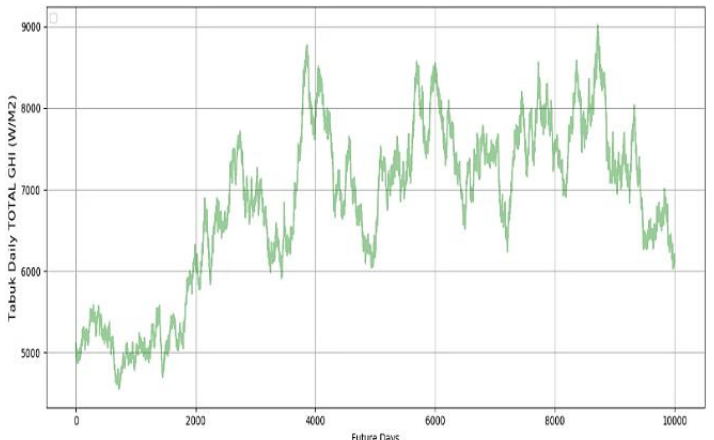

(b)

Figure 8. (a) Daily total solar GHI distributions for the north-western region, as predicted by MCS and $\mathrm{BM}$, and (b) a one-day scenario for the solar GHI distribution prediction performance.

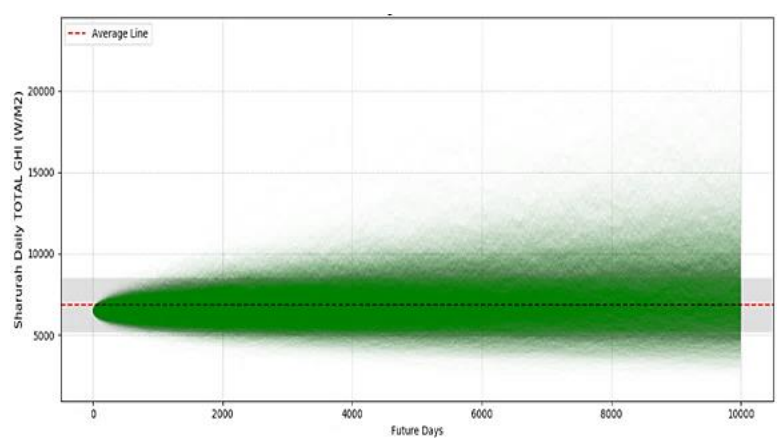

(a)

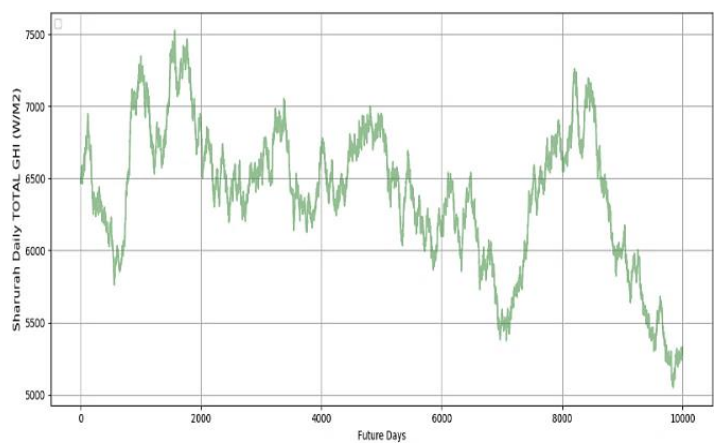

(b)

Figure 9. (a) Daily total solar GHI distributions for the southern region, as predicted by MCS and BM, and (b) a one-day scenario for the solar GHI distribution prediction performance. 


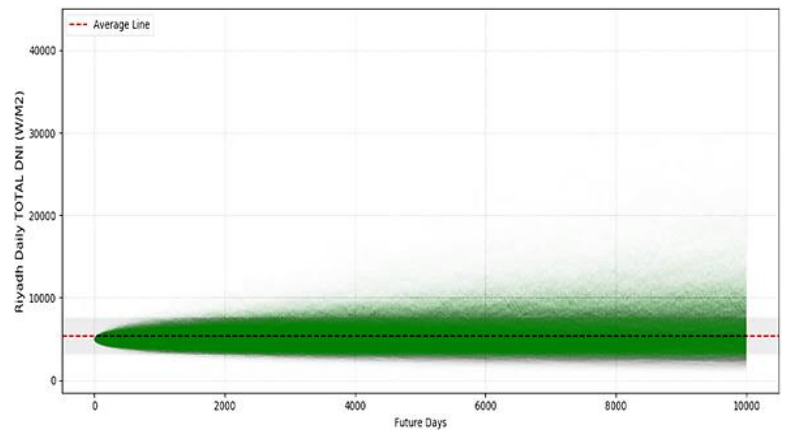

(a)

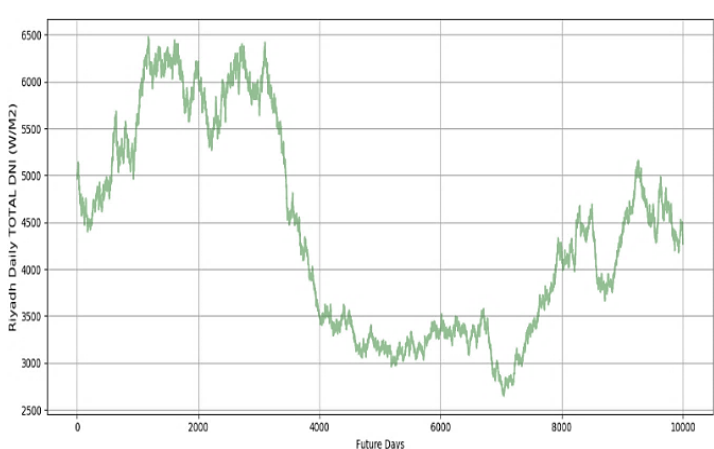

(b)

Figure 10. (a) Daily total solar direct normal irradiance (DNI) distributions for the central region, as predicted by MCS and BM, and (b) a one-day scenario for the solar DNI distribution prediction performance.

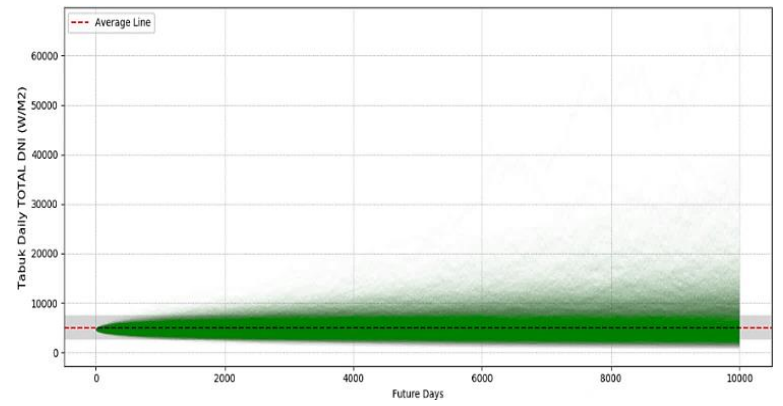

(a)

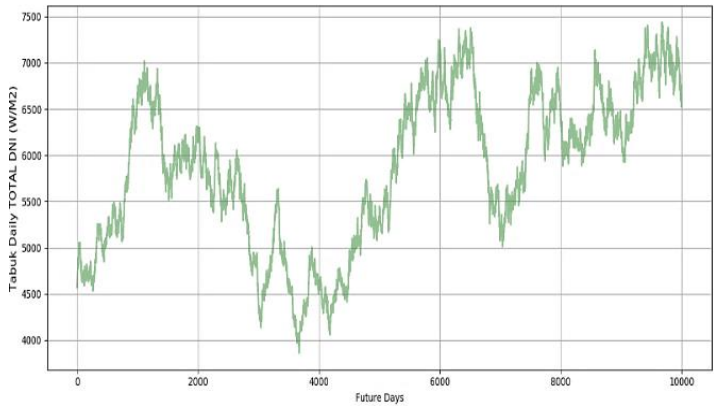

(b)

Figure 11. (a) Daily total solar DNI distributions for the north-western region, as predicted by MCS and BM, and (b) a one-day scenario for the solar DNI distribution prediction performance.

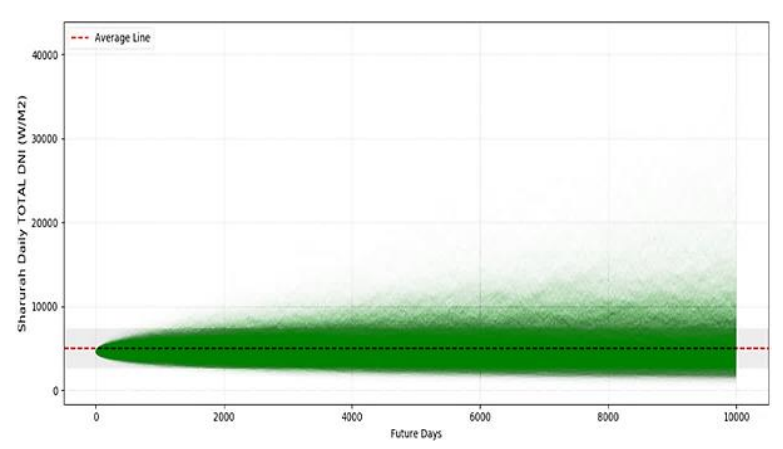

(a)

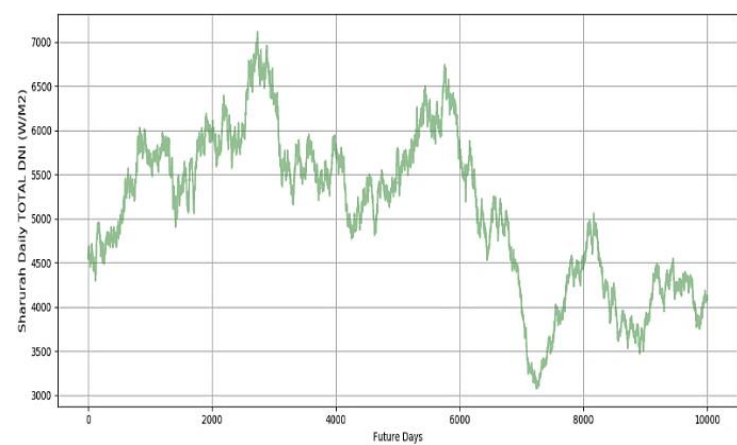

(b)

Figure 12. (a) Daily total solar DNI distributions for the south region, as predicted by MCS and BM, and (b) a one-day scenario for the solar DNI distribution prediction performance. 


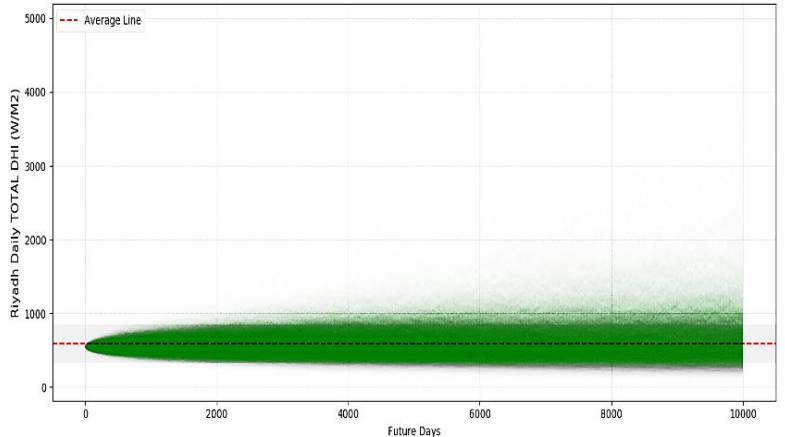

(a)

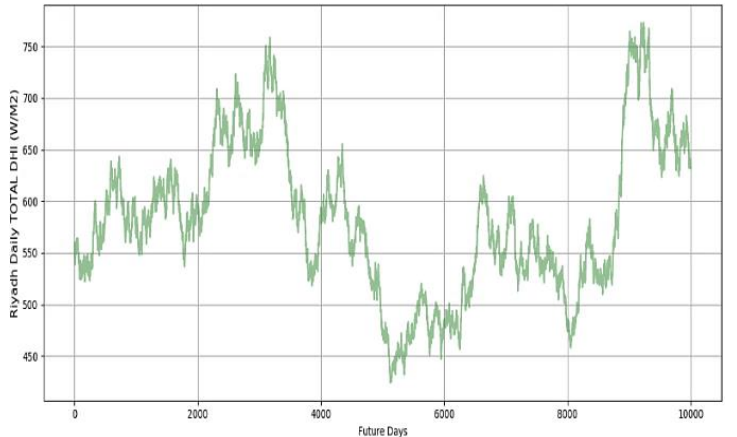

(b)

Figure 13. (a) Daily total solar diffuse horizontal irradiance (DHI) distributions for the central region, as predicted by MCS and BM, and (b) a one-day scenario for the solar DHI distribution prediction performance.

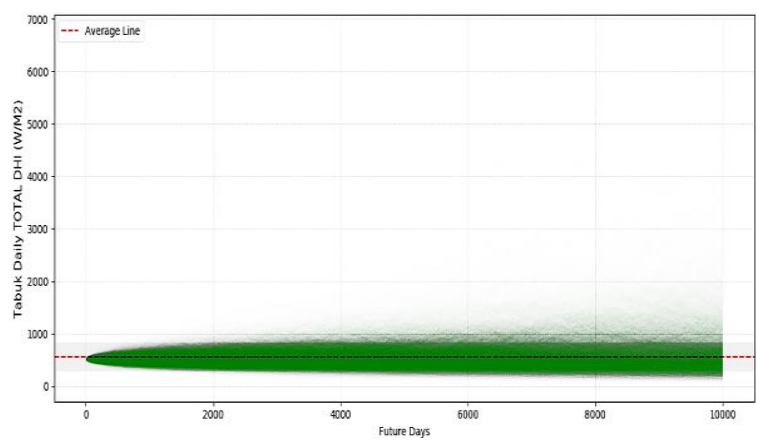

(a)

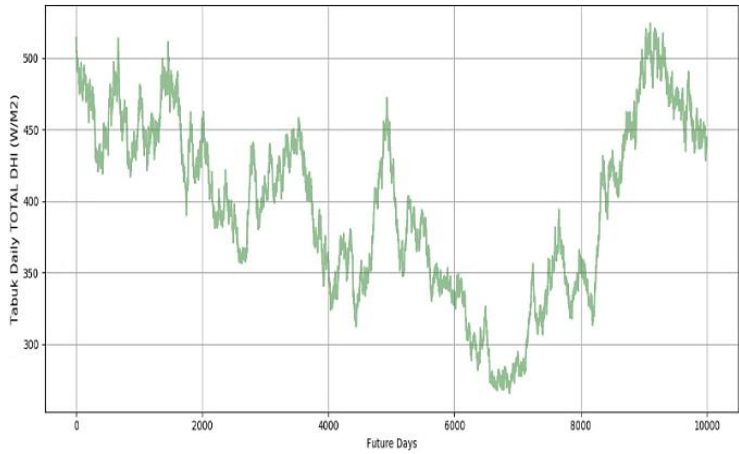

(b)

Figure 14. (a) Daily total solar DHI distributions for the north-western region, as predicted by MCS and BM, and (b) a one-day scenario for the solar DHI distribution prediction performance.

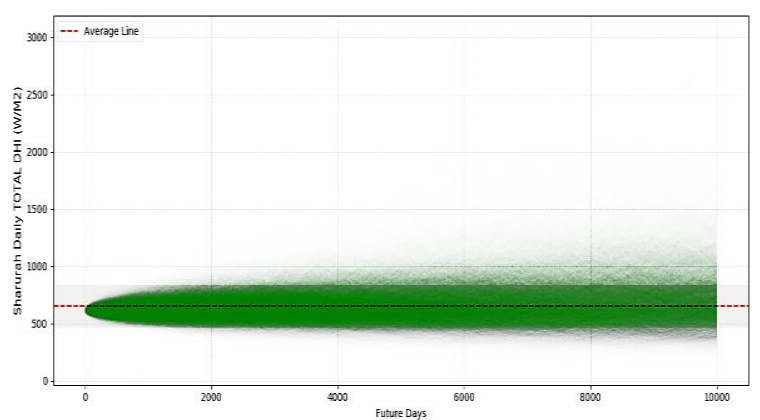

(a)

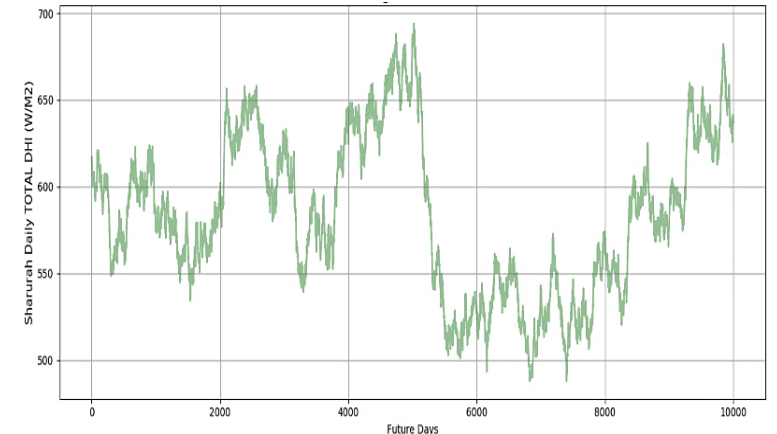

(b)

Figure 15. (a) Daily total solar DHI distributions for the south region, as predicted by MCS and BM, and (b) a one-day scenario for the solar DHI distribution prediction performance. 


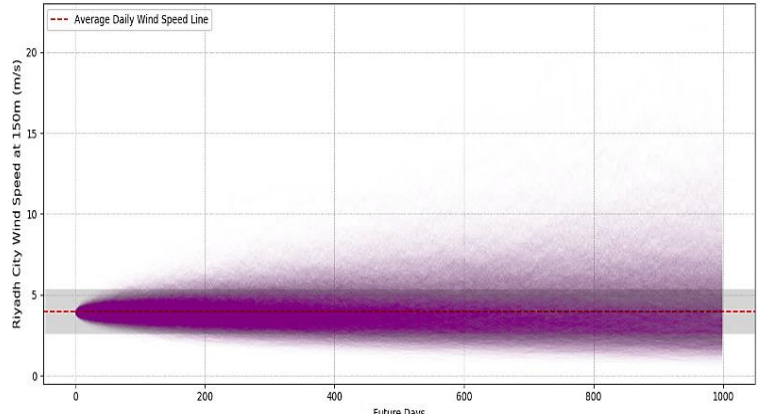

(a)

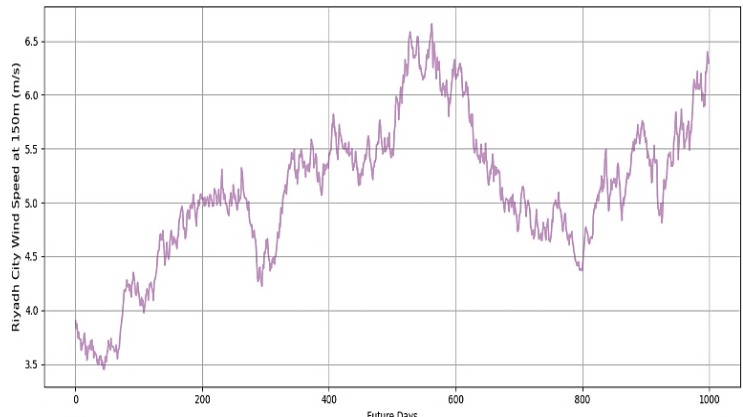

(b)

Figure 16. (a) Average daily wind speed distributions for the central region, as predicted by MCS and $\mathrm{BM}$, and (b) a one-day scenario for the wind speed distribution prediction performance.

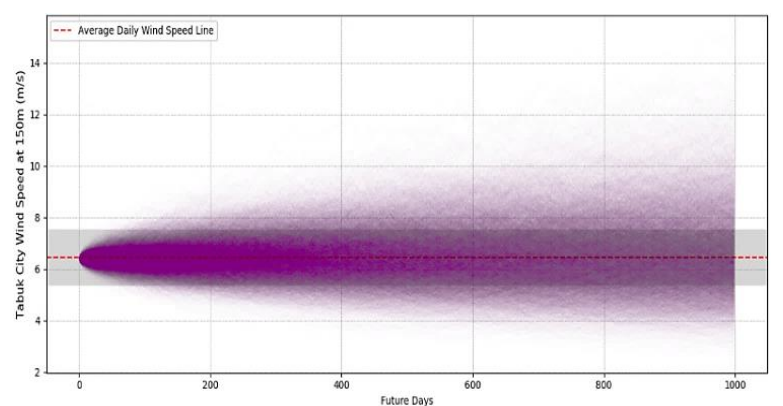

(a)

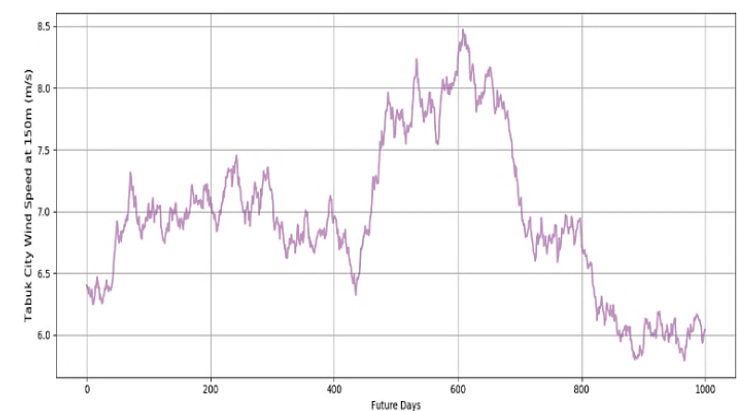

(b)

Figure 17. (a) Average daily wind speed distributions for the north-western region, as predicted by MCS and BM, and (b) a one-day scenario for the wind speed distribution prediction performance.

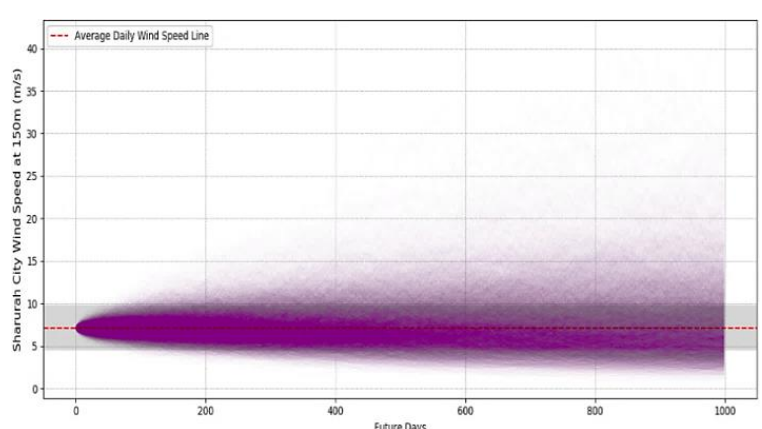

(a)

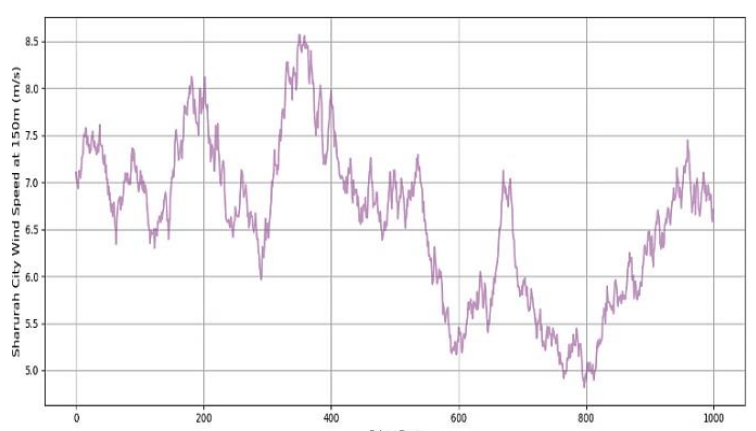

(b)

Figure 18. (a) Average daily wind speed distributions for the southern region, as predicted by MCS, and $\mathrm{BM}$, and (b) a one-day scenario for the wind speed distribution prediction performance. 


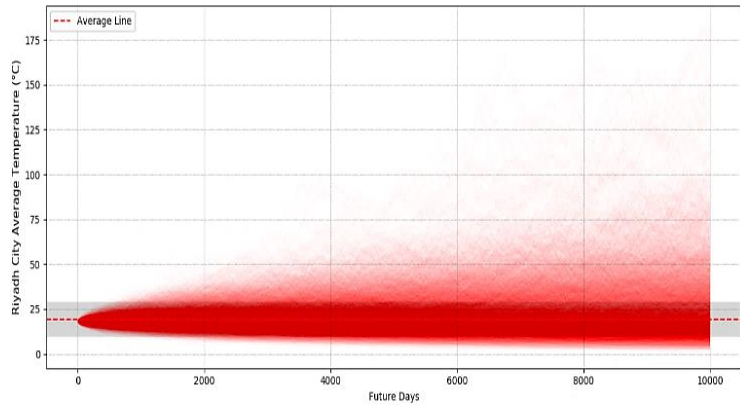

(a)

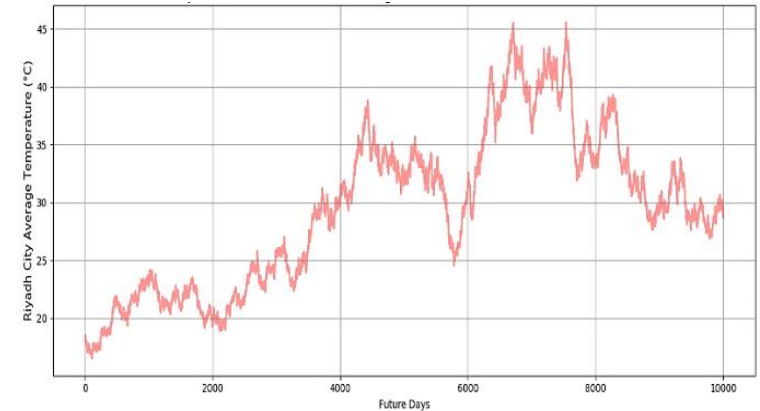

(b)

Figure 19. (a) Average daily temperature distributions for the central region, as predicted by MCS and $\mathrm{BM}$, and (b) a one-day scenario for the temperature distribution prediction performance.

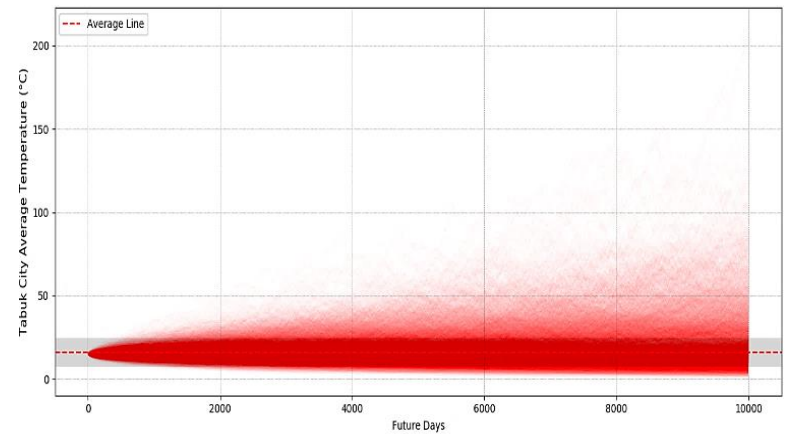

(a)

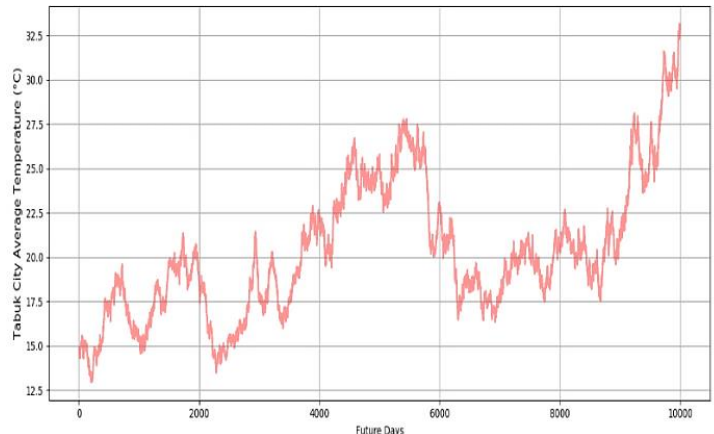

(b)

Figure 20. (a) Average daily temperature distributions for the north-western region, as predicted by MCS and BM, and (b) a one-day scenario for the temperature distribution prediction performance.

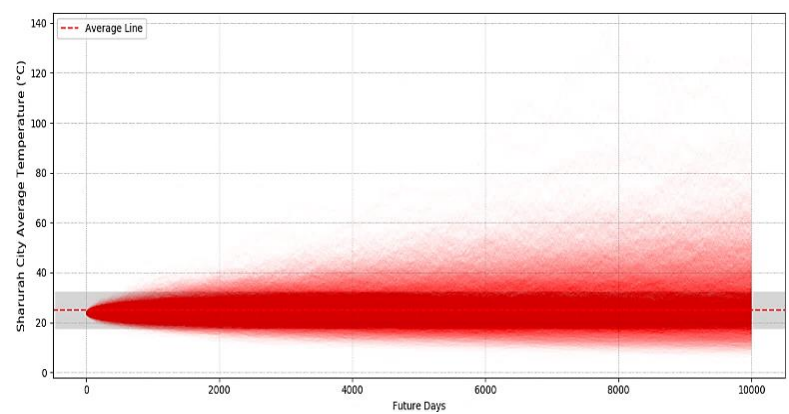

(a)

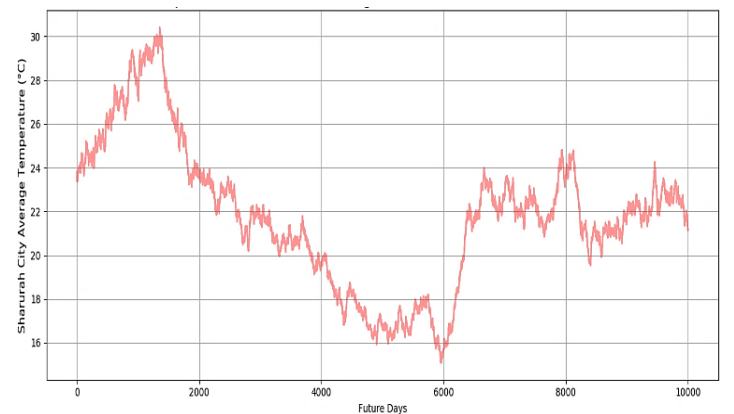

(b)

Figure 21. (a) Average daily temperature distributions for the south-west region, as predicted by MCS and $\mathrm{BM}$, and (b) a one-day scenario for the temperature distribution prediction performance.

\section{Conclusions}

In order to combat climate change issues and promote the implementation of solar and wind technologies as clean energy in Saudi Arabia, the future behaviour of weather resources such as solar irradiances, wind speed potential, and temperature performance were analysed for long-term results. Three regions in Saudi Arabia were selected to be subject to weather analysis and assessment: the central region, the north-western region, and the southern region. The historical daily weather data of the three regions were gathered from eight in-situ radiometer weather stations around Saudi Arabia from the period 1950-2019. The MCS and BM approaches were employed in this research to conduct the future prediction for the solar and wind energy potential and temperature performance. In particular, solar and wind energy fluctuations can be challenges to the selection of both time and 
location for solar and wind energy projects, requiring careful study of the visibility and availability of resources. Fortunately, the variations of solar and wind energy technologies can complement each other. For instance, when solar plants are dormant at night, wind turbines are at work. Solar plants generate maximum power in the summer season and minimum power in the winter.

Based on the results of this research, the north-western region exhibits higher daily total solar GHI and DNI (9050 and $7449 \mathrm{~W} / \mathrm{M}^{2}$, respectively), supported by relatively low temperatures and clean skies. In addition, the north-western region has the best estimated daily average wind speeds (between 5.8 and $8.5 \mathrm{~m} / \mathrm{s}$ ). The second promising region was the southern region, which exposed good daily total values of GHI and DNI (7600 and $7203 \mathrm{~W} / \mathrm{M}^{2}$, respectively). The southern region showed good predictable daily average wind speed performance (between 4.8 and $8.57 \mathrm{~m} / \mathrm{s}$ ), with adequate daily average wind speed distribution for the long-term and low temperature values. According to this research, Saudi Arabia has great opportunities to diversify its power system due to an abundance of potential solar and wind energy resources. Finally, after intensive evaluation and careful analysis of various aspects of solar and wind energy resources in the three studied regions, the north-western region is the most highly recommended region for solar and wind energy applications, followed by the southern region, which also exhibited strong solar and wind energy resources.

Author Contributions: F.A. wrote the main parts of this work, conducted the simulation of the results, and wrote the first draft of this paper. D.C. revised the final version of paper, and the work was under his supervision. All authors read and agreed to the published version of the manuscript.

Funding: This research received no external funding.

Conflicts of Interest: The authors declare no conflict of interest.

\section{References}

1. Rashwan, S.S.; Shaaban, A.M.; Al-Suliman, F. A comparative study of a small-scale solar PV power plant in Saudi Arabia. Renew. Sustain. Energy Rev. 2017, 80, 313-318. [CrossRef]

2. Abdul-Wahab, S.A.; Charabi, Y.; Al-Maamari, R.; Al-Rawas, G.A.; Gastli, A.; Chan, $\mathrm{K} \mathrm{CO}_{2}$ greenhouse emissions in Oman over the last forty-two years. Renew. Sustain. Energy Rev. 2015, 52, 1702-1712. [CrossRef]

3. Hepbasli, A.; Alsuhaibani, Z. A key review on present status and future directions of solar energy studies and applications in Saudi Arabia. Renew. Sustain. Energy Rev. 2011, 15, 5021-5050. [CrossRef]

4. Chen, H.H.; Kang, H.-Y.; Lee, A.H.I. Strategic selection of suitable projects for hybrid solar-wind power generation systems. Renew. Sustain. Energy Rev. 2010, 14, 413-421. [CrossRef]

5. Slootweg, J.G.; Kling, W.L. The impact of large scale wind power generation on power system oscillations. Electr. Power Syst. Res. 2003, 67, 9-20. [CrossRef]

6. Yang, H.; Wei, Z.; Chengzhi, L. Optimal design and techno-economic analysis of a hybrid solar-wind power generation system. Appl. Energy 2009, 86, 163-169. [CrossRef]

7. Bessa, R.; Moreira, C.; Silva, B.; Matos, M. Handling renewable energy variability and uncertainty in power systems operation. Wiley Interdiscip. Rev. Energy Environ. 2014, 3, 156-178. [CrossRef]

8. Al-Abbadi, N.M. Wind energy resource assessment for five locations in Saudi Arabia. Renew. Energy 2005, 30, 1489-1499. [CrossRef]

9. Shafiullah, G.M. Hybrid renewable energy integration (HREI) system for subtropical climate in Central Queensland, Australia. Renew. Energy 2016, 96, 1034-1053. [CrossRef]

10. Al-Alawi, S.M.; Al-Hinai, H.A. An ANN-based approach for predicting global radiation in locations with no direct measurement instrumentation. Renew. Energy 1998, 14, 199-204. [CrossRef]

11. Lopez, G.; Rubio, M.A.; Martınez, M.; Batlles, F.J. Estimation of hourly global photosynthetically active radiation using artificial neural network models. Agric. For. Meteorol. 2001, 107, 279-291. [CrossRef]

12. Mohandes, M.; Rehman, S.; Halawani, T.O. Estimation of global solar radiation using artificial neural networks. Renew. Energy 1998, 14, 179-184. [CrossRef]

13. Ji, G.-R.; Han, P.; Zhai, Y.-J. Wind speed forecasting based on support vector machine with forecasting error estimation. In Proceedings of the 2007 International Conference on Machine Learning and Cybernetics, Hong Kong, China, 19-22 August 2007; pp. 2735-2739.

14. More, A.; Deo, M.C. Forecasting wind with neural networks. Mar. Struct. 2003, 16, 35-49. [CrossRef] 
15. Shafiullah, G.M.; Amanullah, M.T.O.; Ali, A.B.M.S.; Jarvis, D.; Wolfs, P. Prospects of renewable energy-A feasibility study in the Australian context. Renew. Energy 2012, 39, 183-197. [CrossRef]

16. Al-Athel, S.A. Solar energy in the Kingdom of Saudi Arabia. Int. J. Glob. Energy Issues 1997, 9, 53-67.

17. Al-Ansari, J.M.; Bakhsh, H.; Madni, I.K. Wind Energy Atlas for the Kingdom of Saudi Arabia; King Fahd University of Petroleum and Minerals Press: Dhahran, Saudi Arabia, 1986.

18. AlYahya, S.; Irfan, M.A. Analysis from the new solar radiation Atlas for Saudi Arabia. Sol. Energy 2016, 130, 116-127. [CrossRef]

19. Zell, E.; Gasim, S.; Wilcox, S.; Katamoura, S.; Stoffel, T.; Shibli, H.; Engel-Cox, J.; Al Subie, M. Assessment of solar radiation resources in Saudi Arabia. Sol. Energy 2015, 119, 422-438. [CrossRef]

20. Alawaji, S.H.; Eugenio, N.N.; Elani, U.A. Wind energy resource assessment in Saudi Arabia: Part II: Data collection and analysis. Renew. Energy 1996, 9, 818-821. [CrossRef]

21. Alharthi, Y.; Siddiki, M.; Chaudhry, G. Resource Assessment and Techno-Economic Analysis of a Grid-Connected Solar PV-Wind Hybrid System for Different Locations in Saudi Arabia. Sustainability 2018, 10, 3690. [CrossRef]

22. Almarshoud, A.F. Performance of solar resources in Saudi Arabia. Renew. Sustain. Energy Rev. 2016, 66, 694-701. [CrossRef]

23. Ramli, M.A.M.; Hiendro, A.; Al-Turki, Y.A. Techno-economic energy analysis of wind/solar hybrid system: Case study for western coastal area of Saudi Arabia. Renew. Energy 2016, 91, 374-385. [CrossRef]

24. Abu-Hamdeh, N.H.; Alnefaie, K.A. Design considerations and construction of an experimental prototype of concentrating solar power tower system in Saudi Arabia. Energy Convers. Manag. 2016, 117, 63-73. [CrossRef]

25. Dasari, H.P.; Desamsetti, S.; Langodan, S.; Attada, R.; Kunchala, R.K.; Viswanadhapalli, Y.; Knio, O.; Hoteit, I. High-resolution assessment of solar energy resources over the Arabian Peninsula. Appl. Energy 2019, 248, 354-371. [CrossRef]

26. Rehman, S.; Ahmad, A. Assessment of wind energy potential for coastal locations of the Kingdom of Saudi Arabia. Energy 2004, 29, 1105-1115. [CrossRef]

27. Baseer, M.A.; Meyer, J.P.; Alam, M.M.; Rehman, S. Wind speed and power characteristics for Jubail industrial city, Saudi Arabia. Renew. Sustain. Energy Rev. 2015, 52, 1193-1204. [CrossRef]

28. Baseer, M.A.; Meyer, J.P.; Rehman, S.; Alam, M.M. Wind power characteristics of seven data collection sites in Jubail, Saudi Arabia using Weibull parameters. Renew. Energy 2017, 102, 35-49. [CrossRef]

29. Shaahid, S.M.; Al-Hadhrami, L.M.; Rahman, M.K. Economic feasibility of development of wind power plants in coastal locations of Saudi Arabia-A review. Renew. Sustain. Energy Rev. 2013, 19, 589-597. [CrossRef]

30. Rehman, S.; Ahmad, A.; Al-Hadhrami, L.M. Detailed analysis of a 550-MW installed capacity wind farm in Saudi Arabia. Int. J. Green Energy 2010, 7, 410-421. [CrossRef]

31. Elhadidy, M.A.; Shaahid, S.M. Exploitation of renewable energy resources for environment-friendly sustainable development in Saudi Arabia. Int. J. Sustain. Eng. 2009, 2, 56-66. [CrossRef]

32. Rehman, S.; El-Amin, I.M.; Ahmad, F.; Shaahid, S.M.; Al-Shehri, A.M.; Bakhashwain, J.M. Wind power resource assessment for Rafha, Saudi Arabia. Renew. Sustain. Energy Rev. 2007, 11, 937-950. [CrossRef]

33. Yip, C.M.A.; Gunturu, U.B.; Stenchikov, G.L. Wind resource characterization in the Arabian Peninsula. Appl. Energy 2016, 164, 826-836. [CrossRef]

34. Lam, V. Development of Wind Resource Assessment Methods and Application to the Waterloo Region. Master's Thesis, University of Waterloo, Waterloo, ON, USA, 2013.

35. Naik, K. Hands-On Python for Finance: A Practical Guide to Implementing Financial Analysis Strategies Using Python; Packt Publishing Ltd.: Birmingham, UK, 2019; p. 378.

(C) 2020 by the authors. Licensee MDPI, Basel, Switzerland. This article is an open access article distributed under the terms and conditions of the Creative Commons Attribution (CC BY) license (http://creativecommons.org/licenses/by/4.0/). 